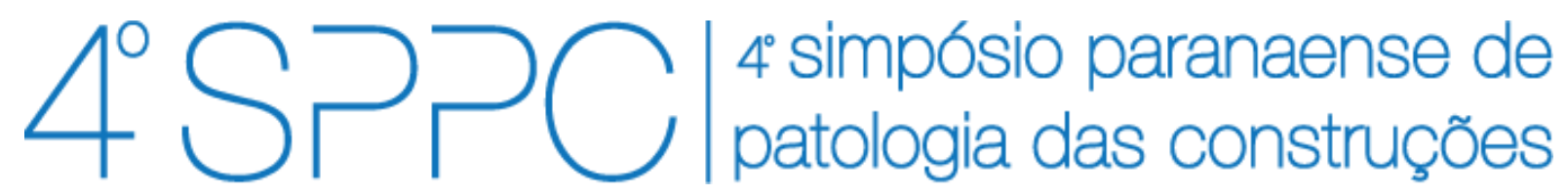

ISSN 2526-7248 artigo n. 4SPPC117, pp. 147-157, 2019

\title{
Compostos cimentícios contaminados por pirita: efeito na resistência à compressão e velocidade de ultrassom
}

\author{
Capraro, Ana Paula Brandão 1; Medeiros, Marcelo Henrique Farias ${ }^{2}$ \\ ${ }_{1}^{1}$ Doutoranda, Universidade Federal do Paraná, anapcapraro@gmail.com \\ ${ }^{2}$ Professor Doutor, Universidade Federal do Paraná, medeiros.ufpr@gmail.com
}

Resumo: Este estudo teve por objetivo avaliar como diferentes teores de contaminação por enxofre influenciam nas propriedades mecânicas e microestruturais de compostos cimentícios. Na pesquisa foi empregada como contaminante a pirita $\left(\mathrm{FeS}_{2}\right)$ e os teores de substituição do agregado miúdo foram: $0,375 \%, 0,75 \%$ e $3,75 \%$, com relação a massa total de agregados da mistura. Para a avaliação do mecanismo foram confeccionados quatro concretos que permaneceram em cura submersa saturada com cal até os 28 dias de idade e após isso, até os 720 dias de idade, foram expostos a uma condição alternada de molhagem e secagem, para acelerar o ataque. Para análise do fenômeno foram realizados os ensaios de resistência à compressão axial, ultrassom e MEV. Como resultados o trabalho apresenta o decréscimo da resistência mecânica para as séries de maior contaminação, bem como a identificação de produtos deteriorantes na matriz cimentícia.

Palavras-chave: contaminação por pirita, compostos cimentícios, durabilidade do concreto, reação sulfática interna.

Abstract: This study aimed to evaluate how different sulfur contamination levels influence the mechanical and microstructural properties of cementitious compounds. In the research the pyrite $\left(\mathrm{FeS}_{2}\right)$ was used as pollutant and the substitute contents of the small aggregate were: $0.375 \%, 0.75 \%$ and $3.75 \%$, relative to the total aggregate mass of the mixture. For the evaluation of the mechanism, four concretes were made that remained in submerged cure saturated with lime until the 28 days of age and after that, until the 720 days of age, were exposed to an alternating condition of wetting and drying, to accelerate the attack. For the analysis of the phenomena were carried out the tests of resistance to axial compression, ultrasound and SEM. As results the work presents the decrease of the mechanical resistance for the series of greater contamination, as well as the identification of deteriorating products in the cement matrix.

Keywords: pyrite contamination, cement compounds, concrete durability, internal sulphate attack. 
CAPRARO, A. P. B.; MEDEIROS, M. H. F., COMPOSTOS CIMENTÍCIOS CONTAMINADOS POR PIRITA: EFEITO NA RESISTÊNCIA À COMPRESSÃO E VELOCIDADE DE ULTRASSOM. $4^{\circ}$ Simpósio Paranaense de Patologia das Construções (40 SPPC), artigo 4SPPC117, pp. 147 - 157, 2019. DOI: 10.4322/2526-7248.037

\section{Introdução}

A durabilidade das estruturas de concreto é uma área de estudo relativamente nova quando comparada a outras da engenharia civil. O concreto por muito tempo foi considerado como um material duradouro, em linhas gerais, que exigiria pouca atenção e manutenção ao longo do tempo [1].

Entretanto, há algumas décadas houve uma grande mudança nesse conceito, de modo que, atualmente, sabe-se que as estruturas de concreto, assim que expostas ao ambiente estão sujeitas a deterioração em função da sua interação com o meio em que esteja em serviço [2]. Glasser et al. [3] destacam que a interação da estrutura de concreto com o meio em que está inserida pode alterar consideravelmente suas propriedades de utilização.

Segundo Coutinho [4], um dos mecanismos de deterioração mais nocivo ao concreto é o ataque por sulfatos. Nesse tipo de agressão, as soluções de sulfatos reagem com os compostos aluminosos ou sílico-aluminosos hidratados do cimento Portland ou com a alumina do agregado, causando expansão, fissuração, desplacamento, amolecimento e desintegração.

$O$ ataque por sulfatos pode acontecer de duas maneiras diferentes. Ele pode ser externo, quando a fonte agressiva está fora do concreto e tende a entrar por sua rede de poros, ou pode ser interno, quando a fonte agressiva já está no concreto, ou seja, faz parte de sua composição.

No caso do ataque interno, o agente agressivo pode ser encontrado nos agregados constituintes do concreto ou na água de amassamento. Segundo Gomides (2009) [5], existe uma motivação para o estudo de agregados contaminados por sulfetos em virtude da constatação da sua presença em sítios geológicos brasileiros.

Segundo Campos et al. [6], o ataque interno por sulfatos, também conhecido como RSI (Reação Sulfática Interna), é um tipo de reação expansiva, menos frequente que a reação álcali-agregado. De acordo com os autores, a forma mais comum de ocorrência do ataque é pela presença de sulfetos (pirrotita e pirita) nos agregados. Os sulfatos, presentes então nos agregados, reagem com os componentes da pasta cimenticia (Portlandida e C-S-H) gerando produtos com potencial expansivo, como é o caso da etringita. A formação da etringita gera variação dimensional, tensões internas e fissuras no concreto, comprometendo a durabilidade das estruturas de concreto [7].

Por causar sérias ações deletérias ao concreto, o emprego de agregados contaminados é controlado por teores máximos sugeridos por normas técnicas nacionais e internacionais.

Para a norma brasileira, NBR 7211 [8], agregados que contenham sulfato $\left(\mathrm{SO}_{4}^{-2}\right)$ podem ser utilizados, desde que o teor total trazido ao concreto por todos os seus componentes (água, agregados, cimento, adições e aditivos químicos) não exceda $0,2 \%$ da massa de cimento.

A norma francesa, AFNOR NF P 18-540 [9], permite o uso desde que o teor de óxido sulfúrico $\left(\mathrm{SO}_{3}\right)$ não ultrapasse $1 \%$ do total de agregados. O mesmo teor é sugerido 
CAPRARO, A. P. B.; MEDEIROS, M. H. F., COMPOSTOS CIMENTÍCIOS CONTAMINADOS POR PIRITA: EFEITO NA RESISTÊNCIA À COMPRESSÃO E VELOCIDADE DE ULTRASSOM. $4^{\circ}$ Simpósio Paranaense de Patologia das Construções (40 SPPC), artigo 4SPPC117, pp. 147 - 157, 2019. DOI: 10.4322/2526-7248.037

pela norma Espanhola-Europeia, UNE EN 1744-1 [10], porém a porcentagem é com relação ao peso total da amostra de concreto.

Já o Instituto Americano do Concreto $(A C I)$ 201.2R-01 [11] é um pouco mais rígido, estabelecendo uma porcentagem limite de $\mathrm{SO}_{3}$ igual a $0,5 \%$ com relação ao peso total de agregado.

Levando em consideração as informações expostas nesse item, o presente trabalho tem por objetivo avaliar as variações nas propriedades, mecânicas e microestruturais, de concretos dosados com diferentes teores de contaminação por enxofre.

\section{Materiais e métodos}

Para a avaliação do desempenho dos concretos contaminados com diferentes teores de enxofre foram adotadas quatro séries de estudo, sendo uma delas a referência, sem nenhuma contaminação, e outras três com diferentes teores de substituição do agregado miúdo por pirita.

Com o intuito de acompanhar o mecanismo de deterioração nos concretos estudados foram realizados três ensaios: o de resistência à compressão axial, o de ultrassom e MEV.

\subsection{Materiais}

O aglomerante empregado no estudo foi composto em laboratório, substituindo-se $35 \%$ do CP V - ARI por cinza volante, de modo a aproximar esta mistura de aglomerantes ao cimento tipo CP IV de acordo com a NBR 5736 [12].

Foi feita a escolha do cimento CP IV por este ser muito utilizado em barragens de concreto. Não foi usado diretamente um cimento CP IV comercial porque, neste caso, não se tem a informação do teor exato de pozolana na mistura.

O cimento CP V - ARI empregado possuía massa específica de $3,13 \mathrm{~g} / \mathrm{cm}^{3}$ e uma área específica BET de $1,07 \mathrm{~m}^{2} / \mathrm{g}$. Por outro lado, a cinza volante, proveniente da combustão do carvão mineral da jazida do vale do rio Tubarão, apresentou massa específica de $1,95 \mathrm{~g} / \mathrm{cm}^{3}$ e área específica BET de 1,09 m²/g.

O agregado miúdo empregado foi uma areia natural, proveniente da região de São Luiz do Purunã, no Paraná. As características físicas principais do material como: a massa específica; a massa unitária; o teor de material pulverulento; e o módulo de finura; foram obtidas com base nas recomendações normativas e estão apresentados na Tabela 1.

Tabela 1: Caracterização do agregado miúdo utilizado nas dosagens de concreto

\begin{tabular}{ccc}
\hline Propriedade & Valores obtidos no teste & Norma técnica \\
\hline Massa Específica, $\mathrm{g} / \mathrm{cm}^{3}$ & 2,38 & NBR NM 52 [13] \\
Massa Unitária, $\mathrm{Kg} / \mathrm{m}^{3}$ & 1490 & NBR NM 45 [14] \\
Teor de pulverulentos, \% & 10,13 & NBR NM 46 [15] \\
Módulo de finura & 1,41 & NBR NM 248 [16] \\
\hline
\end{tabular}


CAPRARO, A. P. B.; MEDEIROS, M. H. F., COMPOSTOS CIMENTÍCIOS CONTAMINADOS POR PIRITA: EFEITO NA RESISTÊNCIA À COMPRESSÃO E VELOCIDADE DE ULTRASSOM. 40 Simpósio Paranaense de Patologia das Construções (40 SPPC), artigo 4SPPC117, pp. 147 - 157, 2019. DOI: 10.4322/2526-7248.037

O agregado graúdo utilizado foi uma brita 1, proveniente da região de Curitiba, Paraná. O material foi um basalto com diques de diabásio e suas características físicas estão apresentadas na Tabela 2.

Tabela 2: Caracterização do agregado graúdo utilizado nas dosagens de concreto

\begin{tabular}{ccc}
\hline Propriedade & Valores obtidos no teste & Norma técnica \\
\hline Massa Específica, $\mathrm{g} / \mathrm{cm}^{3}$ & 2,72 & NBR NM 53 [17] \\
Massa Unitária, $\mathrm{Kg} / \mathrm{m}^{3}$ & 1625 & NBR NM 45 [14] \\
Absorção, \% & 0,98 & NBR NM 53 [17] \\
Dimensão máxima & 19,1 & NBR NM 248 [16] \\
característica, mm & 6,8 & NBR NM 248 [16] \\
Módulo de finura &
\end{tabular}

Nenhum dos agregados empregados possuiu, em sua composição, a contaminação natural pelo íon sulfeto. Dessa forma, optou-se pela contaminação artificial do agregado miúdo, substituindo parte de sua massa por pirita.

A pirita utilizada foi proveniente da região de Figueira, no Paraná. Esse material foi obtido de um resíduo do processo de beneficiamento do carvão mineral. Nos ensaios de caracterização o material apresentou massa específica igual a 4,95 g/cm³ e, após o seu processo de moagem, foi classificada como um material passante pela peneira $2,4 \mathrm{~mm}$.

\subsection{Preparo das amostras}

Para a realização dos ensaios de resistência à compressão axial e o de propagação de ondas de ultrassom foram moldados corpos de prova cilíndricos, de $(10 \times 20) \mathrm{cm}$, seguindo as recomendações da NBR 5738 [18]. Já para o ensaio de MEV foram moldadas pequenas amostras, do mesmo material, de aproximadamente $20 \mathrm{ml}$.

Os corpos de prova cilíndricos foram moldados conforme as recomendações da NBR 5738 [18].

O traço adotado como referência (traço médio de concreto convencional empregado em usina hidroelétrica nacional) foi de 1:2,70:2,70 e a relação água/cimento de 0,60.

Para este estudo foram estabelecidos 4 teores de contaminação do material por $\mathrm{SO}_{3}$, com base no que preconiza o ACl 201.2R-01 [11], sendo dois teores abaixo do limite de norma: o de referência (0,0\%); e com 0,5\%, em massa, de $\mathrm{SO}_{3}$; e 2 teores acima desde limite: um contendo $1 \%$, em massa, de $\mathrm{SO}_{3}$; e outro com $5 \%$, em massa, deste mesmo contaminante. Neste artigo os traços estão nomeados como $0,0 \% \mathrm{SO}_{3}$; $0,5 \% \mathrm{SO}_{3} ; 1,0 \% \mathrm{SO}_{3}$ e $5,0 \% \mathrm{SO}_{3}$. 
CAPRARO, A. P. B.; MEDEIROS, M. H. F., COMPOSTOS CIMENTÍCIOS CONTAMINADOS POR PIRITA: EFEITO NA RESISTÊNCIA À COMPRESSÃO E VELOCIDADE DE ULTRASSOM. $4^{\circ}$ Simpósio Paranaense de Patologia das Construções (40 SPPC), artigo 4SPPC117, pp. 147 - 157, 2019. DOI: 10.4322/2526-7248.037

Como no estudo foi empregada a pirita como contaminante, foi necessária a multiplicação dos teores por um fator proporcional em quantidade de enxofre entre os dois compostos. Na Tabela 3, estão apresentados os teores de contaminação empregados, em $\mathrm{SO}_{3}$ e $\mathrm{FeS}_{2}$.

Tabela 3: Teores proporcionais de contaminação em $\mathrm{SO}_{3}$ e pirita

\begin{tabular}{cc}
\hline Teor de $\mathrm{SO}_{3}$ & Teor de pirita \\
\hline $0,00 \%$ & $0,00 \%$ \\
$0,50 \%$ & $0,38 \%$ \\
$1,00 \%$ & $0,75 \%$ \\
$5,00 \%$ & $3,75 \%$ \\
\hline
\end{tabular}

As porcentagens de contaminação foram aplicadas sobre a massa total de agregados e a substituição foi feita com o agregado miúdo, material com granulometria similar à pirita.

Após a desforma, até os 28 dias de idade, as amostras foram mantidas em cura úmida saturada com cal. Após esse período, para a aceleração do mecanismo de degradação, foi adotado um procedimento semanal de molhagem e secagem, sendo este já empregado por outros autores, como: GAO et al. [19], GONG et al. [20] e JIANG et al. [21]. O método deste estudo consistiu em alternar semanalmente as amostras entre uma condição de imersão, em um tanque com solução aquosa continuamente aerada por um sistema de borbulhamento, e, a uma câmara seca com UR de $(55 \pm 5) \%$ e à temperatura média de $(23 \pm 2)^{\circ} \mathrm{C}$.

\subsection{Ensaios}

Os ensaios de resistência à compressão axial e ultrassom foram realizados em cinco idades distintas dos concretos, sendo elas: 28, 84, 168, 360 e 720 dias. O ensaio de MEV foi realizado na idade mais avançada do estudo, isto é, 720 dias, de forma a avaliar um estágio avançado do ataque e possibilitar correlações com os demais ensaios.

Os ensaios realizados nos corpos de prova cilíndricos foram o de resistência à compressão axial e velocidade de propagação de ondas de ultrassom.

O ensaio de resistência à compressão axial foi realizado em conformidade à NBR 5739 [22], em uma prensa alemã VEB WERKSTOFFPROFMASCHINEN LEIPZIG (VWM), com capacidade de carga igual $100 \mathrm{tf}$ e velocidade de carregamento de $(0,45$ $\pm 0,15) \mathrm{MPa} / \mathrm{s}$. O de ultrassom foi realizado conforme a NBR 8802 [23], ensaio este que tem por objetivo determinar a velocidade de propagação de ondas no interior dos corpos de prova cilíndricos.

Por fim, foi realizado o ensaio de MEV. Na idade de 720 dias as amostras tiveram suas reações de hidratação paralisadas, procedimento este feito em conformidade com o descrito por Duart [24]. As amostras eram retiradas da condição em que estavam, fragmentadas em pedaços e imergidas em álcool etílico p.a. por 24 horas. Após esse período, as amostras eram retiradas do álcool e colocadas em estuda a 
CAPRARO, A. P. B.; MEDEIROS, M. H. F., COMPOSTOS CIMENTÍCIOS CONTAMINADOS POR PIRITA: EFEITO NA RESISTÊNCIA À COMPRESSÃO E VELOCIDADE DE ULTRASSOM. 40 Simpósio Paranaense de Patologia das Construções (40 SPPC), artigo 4SPPC117, pp. $147-157$, 2019. DOI: 10.4322/2526-7248.037

$40^{\circ} \mathrm{C}$ por 24 horas. Ao fim do processo, as amostras eram armazenadas em um dessecador contendo sílica gel até o momento de realização do ensaio.

As imagens de microscopia foram obtidas com um microscópio FEG SEM, Tescan, Mira 3 e microssonda analítica de raios-X Oxford X-Max 50 (EDS). No momento de obtenção das imagens foi adicionada uma fita de carbono, colada as amostras, para torna-las condutoras e permitir o fluxo de elétrons em seu interior, já que o ensaio foi feito na superfície de fratura da amostra.

\subsection{Análise dos resultados}

Os resultados obtidos com os ensaios propostos no programa experimental foram tratados estatisticamente por meio do teste de Tukey, com 95\% de confiança.

Além disso, foram consideradas válidas as leituras obtidas quando os valores individuais não diferiram da média em mais de 10\%.

\section{Resultados e discussões}

Na Fig. 1 estão mostrados os resultados médios da resistência à compressão axial, em função do teor de contaminação por $\mathrm{SO}_{3}$ e das idades de envelhecimento $(28,84$, 168,360 e 720 dias).

Na primeira idade avaliada, aos 28 dias, foi notada equivalência estatística entre todas as séries estudadas, não sendo notada uma diferença comportamental nesse parâmetro avaliado. A partir dos 84 dias de idade a série de maior contaminação, $5,0 \% \mathrm{SO}_{3}$, começou a apresentar diferenças significativas com as demais séries, indicando prejuízo na propriedade por conta do alto teor de contaminação. Nota-se também que dos 28 para os 84 dias de idade todas as séries apresentaram ganho de resistência, válido estatisticamente. O ganho de resistência em idade avançada é justificado, neste caso, pelo alto teor de adição pozolânica (35\%) empregado em conjunto com o cimento CP V ARI, a cinza volante.

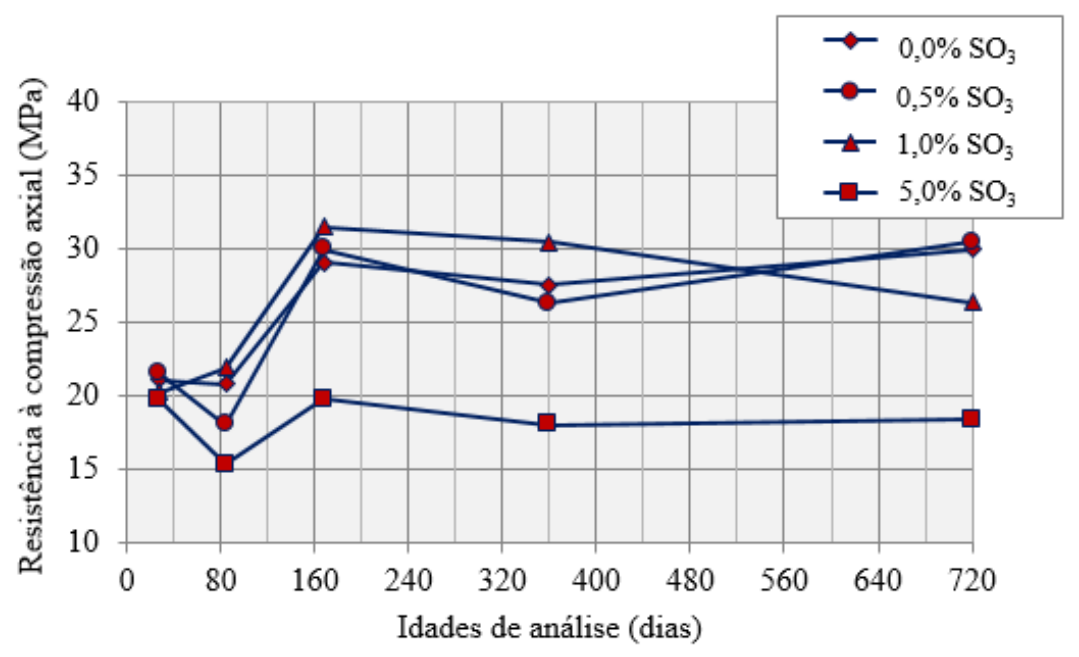

Figura 1: Resistência à compressão axial das séries $0,0 \% \mathrm{SO}_{3} ; 0,5 \% \mathrm{SO}_{3} ; 1,0 \%$ $\mathrm{SO}_{3} ; 5,0 \% \mathrm{SO}_{3}$ na condição de ciclagem de molhagem e secagem 
CAPRARO, A. P. B.; MEDEIROS, M. H. F., COMPOSTOS CIMENTÍCIOS CONTAMINADOS POR PIRITA: EFEITO NA RESISTÊNCIA À COMPRESSÃO E VELOCIDADE DE ULTRASSOM. $4^{\circ}$ Simpósio Paranaense de Patologia das Construções (40 SPPC), artigo 4SPPC117, pp. 147 - 157, 2019. DOI: 10.4322/2526-7248.037

A série com $1 \%$ de $\mathrm{SO}_{3}$ pode ser considerada, aos 360 dias como a série de maior resistência, apresentando diferenças estatísticas significativas. Isso foi notado e apresentado por outros autores, como é o caso de Pereira [25] e Oliveira [26]. Os autores explicam que em idades iniciais as séries contaminadas com pequenos percentuais podem apresentar aumento de resistência pela colmatação dos poros pelos produtos gerados no ataque. Esse aumento ocorre até a completa ocupação dos poros e o início do surgimento de fissuras, quando há o decréscimo de resistência. Essa situação pode já ter ocorrido com a série de $1 \%$ de $\mathrm{SO}_{3}$, já que aos 720 dias de idade pode ser considerada menos resistente que a série referência e a de $0,5 \%$ de $\mathrm{SO}_{3}$.

Ao longo de todas as idades analisadas, as séries $0,0 \% \mathrm{SO}_{3}$ e $0,5 \% \mathrm{SO}_{3}$ puderam ser consideradas equivalentes estatisticamente, não sendo possível acusar prejuízo na propriedade pela presença de $\mathrm{SO}_{3}$ neste teor.

O ensaio de propagação de ondas de ultrassom apresentou resultados um pouco diferentes dos observados no ensaio de compressão axial. Neste caso, como pode ser observado na Fig. 2, a série de $1,0 \%$ de $\mathrm{SO}_{3}$ apresentou os maiores resultados ao longo de todo estudo, mantendo na idade de 720 dias. Neste caso, a densificação da matriz, pela colmatação dos poros, pode ter auxiliado na propagação de ondas de modo que a velocidade fosse maior.

Por outro lado, a série de maior contaminação $\left(5,0 \% \mathrm{SO}_{3}\right)$ possivelmente tenha superado a densificação e já tenha em seu interior fissuras causadas pelo ataque, uma vez que o resultado observado foi menor do que da série referência. Ao final do estudo observa-se grande semelhança entre os resultados observados no ensaio de resistência e o de ultrassom, indicando a série de maior contaminação como a de menor resistência e menor velocidade de propagação.

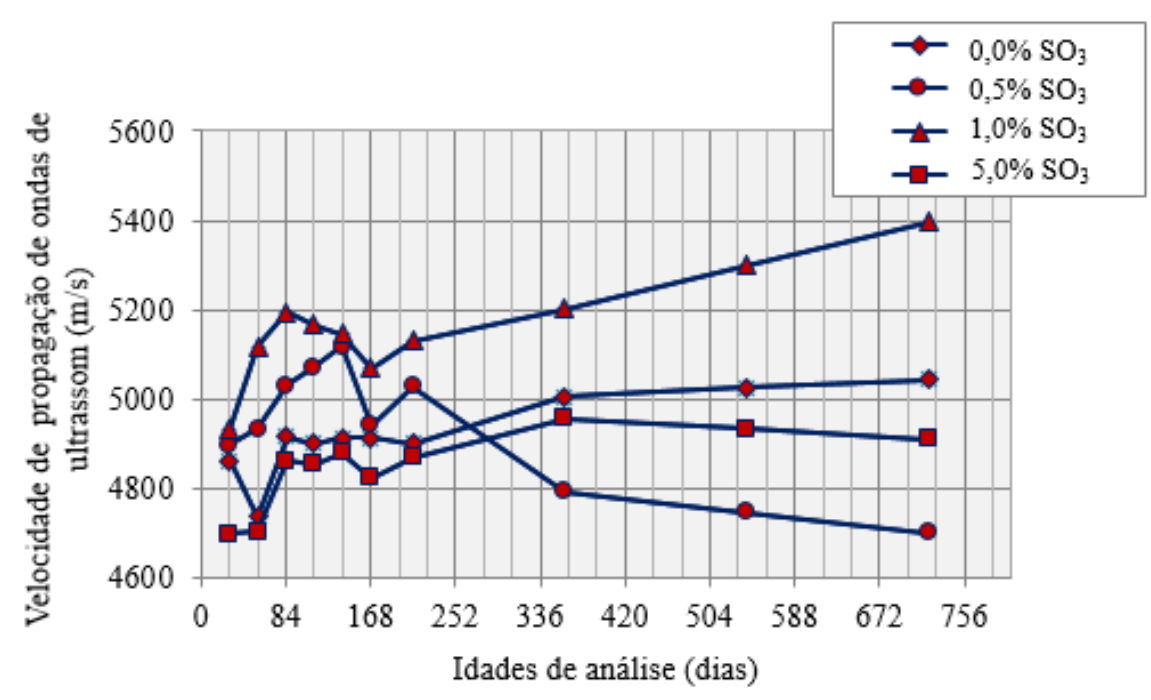

Figura 2: Velocidade de propagação de ondas de ultrassom das séries $0,0 \% \mathrm{SO}_{3}$; $0,5 \% \mathrm{SO}_{3} ; 1,0 \% \mathrm{SO}_{3} ; 5,0 \% \mathrm{SO}_{3}$ na condição de ciclagem de molhagem e secagem. 
CAPRARO, A. P. B.; MEDEIROS, M. H. F., COMPOSTOS CIMENTÍCIOS CONTAMINADOS POR PIRITA: EFEITO NA RESISTÊNCIA À COMPRESSÃO E VELOCIDADE DE ULTRASSOM. 40 Simpósio Paranaense de Patologia das Construções (40 SPPC), artigo 4SPPC117, pp. 147 - 157, 2019. DOI: 10.4322/2526-7248.037

Por fim, no ensaio de microscopia eletrônica de varredura foi possível observar os produtos oriundos do ataque interno de sulfatos para a série de maior contaminação $\left(5,0 \% \mathrm{SO}_{3}\right)$. Na Fig. 3 é apresentada a análise comparativa entre a série referência ( $A$ e B) e a de maior contaminação ( $C$ e D). Nas imagens obtidas da amostra contaminada é possível identificar cristais com aspectos semelhantes aos cristais de etringita, suspeita essa confirmada pelo EDS.

A amostra referência, por outro lado, apresentou vazios sem a presença dos cristais pontiagudos, mostrando-se integra, uma vez que não possui contaminação.

Essas imagens corroboram os ensaios de compressão axial e velocidade de propagação de ondas de ultrassom, uma vez que há o indicativo de fragilidade da matriz pela presença dos cristais expansivos e frágeis.
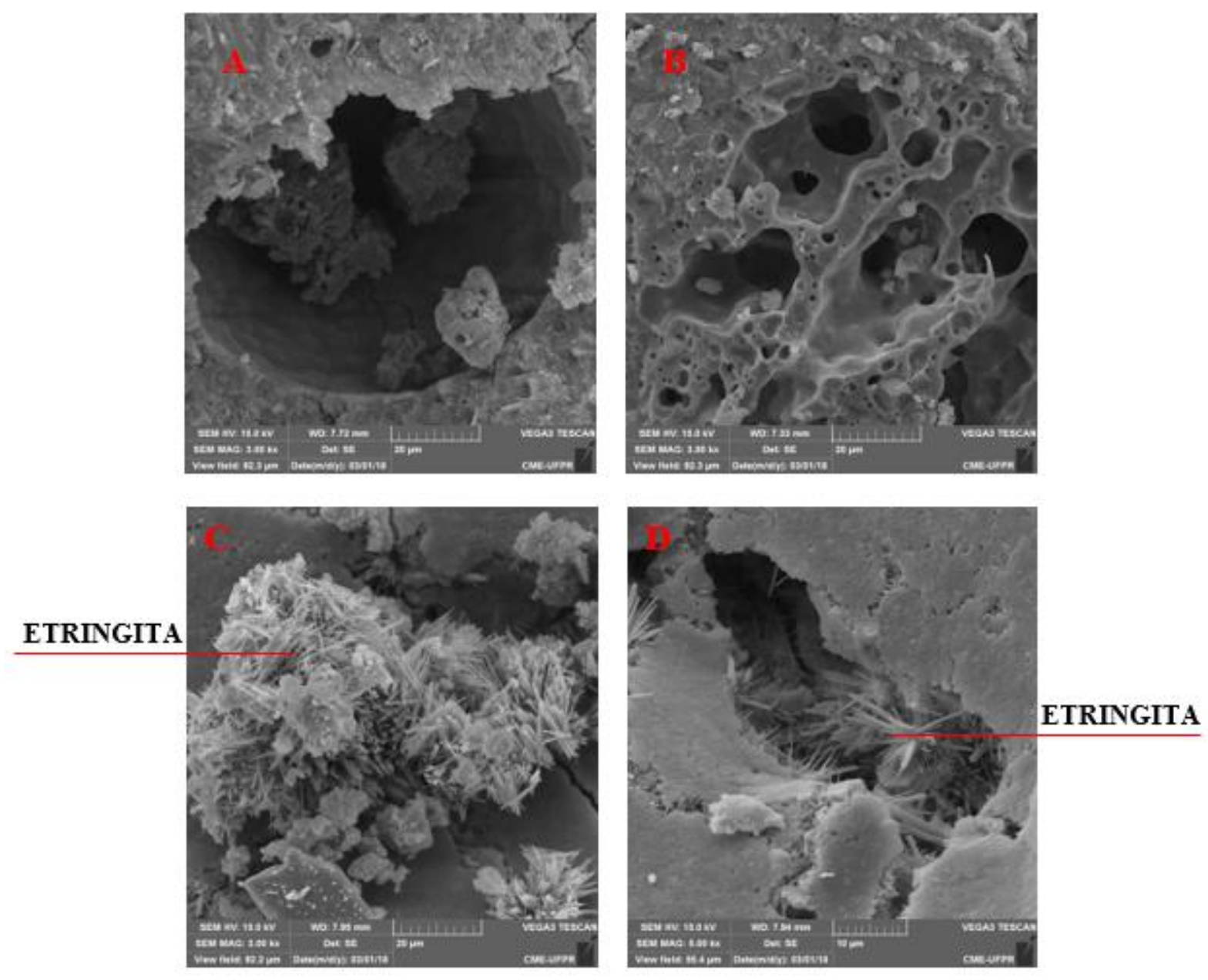

Figura 3: Imagens de MEV obtidas para as séries referência ( $A$ e $B$ ) e de maior contaminação ( $C$ e $D)$ na condição de ciclagem de molhagem e secagem. 
CAPRARO, A. P. B.; MEDEIROS, M. H. F., COMPOSTOS CIMENTÍCIOS CONTAMINADOS POR PIRITA: EFEITO NA RESISTÊNCIA À COMPRESSÃO E VELOCIDADE DE ULTRASSOM. 40 Simpósio Paranaense de Patologia das Construções (40 SPPC), artigo 4SPPC117, pp. $147-157$, 2019. DOI: 10.4322/2526-7248.037

\section{Conclusões}

O trabalho experimental desenvolvido neste artigo permite realizar as conclusões listadas a seguir:

- Aos 720 dias de idade, para a condição acelerada estudada, a resistência da série $5,0 \%$ de $\mathrm{SO}_{3}$ foi $40 \%$ menor que da série referência $\left(0,0 \% \mathrm{SO}_{3}\right)$;

- O teor de $1,0 \%$ de $\mathrm{SO}_{3}$ apresentou os maiores valores para o ensaio de propagação de ondas de ultrassom, podendo indicar ainda a fase de colmatação dos poros, por produtos oriundos do ataque;

- O ensaio de MEV corroborou com os demais, indicando a fragilidade de amostras contaminadas pela presença de cristais de etringita;

- Analisando os teores empregados de contaminação (0,5\%,1,0\% e 5,0\% de $\mathrm{SO}_{3}$ ) notou-se maior diferença comportamental das séries de 1,0\% e 5,0\% com relação à série referência. Nos ensaios realizados a série de $0,5 \%$ de $\mathrm{SO}_{3}$ obteve resultados próximos à série de $0,0 \%$ de $\mathrm{SO}_{3}$, com excessão do ensaio de ultrassom. O comportamento semelhante ao da série referência de acordo com o limite estabelecido pelo comitê americano [11].

\section{Agradecimentos}

Os autores agradecem à infraestrutura e ao apoio em recursos humanos e financiamento à Coordenação de Aperfeiçoamento de Pessoal de Nível Superior (CAPES), à Fundação Araucária, ao Conselho Nacional de Desenvolvimento Científico e Tecnológico (CNPq) e à Universidade Federal do Paraná PPGECC/UFPR.

\section{Referências}

[1] Medeiros, M. H. F.; Andrade, J. J. O.; Helene, P. (2011) Durabilidade e vida útil das estruturas de concreto. Concreto: Ciência e Tecnologia - IBRACON.

[2] Roque, J. A.; Moreno Junior, A. L. (2005) Considerações sobre vida útil do concreto. $1^{\circ}$ Encontro Nacional de Pesquisa, Projeto e Produção em concreto Pré-moldado. São Carlos.

[3] Glasser, P. F.; Marchand, J.; Samsom, E. (2008) Durability of concrete Degradation phenomena involving detrimental chemical reactions. Cement and Concrete Research. v. 2, p. 226-246.

[4] Coutinho, J. S. (2001) Ataque por Sulfatos. Faculdade de Engenharia do Porto (FEUP). Portugal.

[5] Gomides, M. J. (2009) Investigação de agregados contendo sulfetos e seus efeitos sobre a durabilidade do concreto. Tese (Doutorado), Universidade Federal do Rio Grande do Sul, Porto Alegre, Brasil. 
CAPRARO, A. P. B.; MEDEIROS, M. H. F., COMPOSTOS CIMENTÍCIOS CONTAMINADOS POR PIRITA: EFEITO NA RESISTÊNCIA À COMPRESSÃO E VELOCIDADE DE ULTRASSOM. $4^{\circ}$ Simpósio Paranaense de Patologia das Construções (40 SPPC), artigo 4SPPC117, pp. 147 - 157, 2019. DOI: 10.4322/2526-7248.037

[6] Campos, A.; López, C. M.; Blanco, A.; Aguado, A. (2018) Effects of an internal sulfate attack and an alkali-aggregate reaction in a concrete dam. Construction and Building Materials. Vol. 166. pp. 668-683.

[7] Oliveira, I.; Cavalaro, S. H. P.; Aguado, A. (2013) New kinetic model to quantify the internal sulfate attack in concrete. Cement and Concrete Research. Vol. 43, pp. 95-104.

[8] Associação Brasileira de Normas Técnicas. ABNT: NBR 7211 (2009): Agregados para concreto - Especificação.

[9] Association Française de Normalisation. AFNOR NF P 18-540 (1997). Granulats - Définitions, conformité, spécifications.

[10] Comité Técnico de Normalización. UNE-EM 1744-1 (199).Determinación del contenido total de azufre expresado em SO3 y determinación del contenido de húmus.

[11] American Concrete Institute ACI 201 (1991). Guide to Durable Concrete. Detroit - USA.

[12] Associação Brasileira de Normas Técnicas. ABNT: NBR 5736 (1991). Cimento Portland pozolânico.

[13] Associação Brasileira de Normas Técnicas. ABNT: NBR NM 52 (2009). Agregado miúdo - Determinação da massa específica e massa específica aparente.

[14] Associação Brasileira de Normas Técnicas. ABNT: NBR NM 45 (2006). Agregados - Determinação da massa unitária e do volume de vazios.

[15] Associação Brasileira de Normas Técnicas. ABNT: NBR NM 46 (2003). Agregados - Determinação do material fino que passa através da peneira 75 um, por lavagem.

[16] Associação Brasileira de Normas Técnicas. ABNT: NBR NM 248 (2003). Agregados - Determinação da composição granulométrica.

[17] Associação Brasileira de Normas Técnicas. ABNT: NBR NM 53 (2009). Agregado graúdo - Determinação da massa específica, massa específica aparente e absorção de água.

[18] Associação Brasileira de Normas Técnicas. ABNT: NBR 5738 (2015). Concreto - Procedimento para moldagem e cura de corpos de prova.

[19] Gao, J.; Yu, Z.; Song, L.; Wang, T.; Wei, S. (2013) Durability of concrete exposed to sulfate attack under flexural loading and drying-wetting cycles. Construction and Building Materials. Vol. 39 pp. 33-38.

[20] Gong, J.; Cao, J.; Wang, Y. (2016) Effects of sulfate attack and dry-wet circulation on creep of fly-ash slag concrete. Construction and Building Materials. Vol.125 pp.12-20.

[21] Jiang, L.; Niu, D. (2016) Study of deterioration of concrete exposed to different types of sulfate solutions under drying-wetting cycles. Construction and Building Materials. Vol. 117. pp. 88-98. 
CAPRARO, A. P. B.; MEDEIROS, M. H. F., COMPOSTOS CIMENTÍCIOS CONTAMINADOS POR PIRITA: EFEITO NA RESISTÊNCIA À COMPRESSÃO E VELOCIDADE DE ULTRASSOM. $4^{\circ}$ Simpósio Paranaense de Patologia das Construções (40 SPPC), artigo 4SPPC117, pp. 147 - 157, 2019. DOI: 10.4322/2526-7248.037

[22] Associação Brasileira de Normas Técnicas. ABNT: NBR 5739 (2007). Concreto - Ensaios de compressão de corpos de prova cilíndricos.

[23] Associação Brasileira de Normas Técnicas. ABNT: NBR 8802 (2015). Concreto endurecido - Determinação da velocidade de propagação de onda ultrassônica.

[24] Duart, M. A. (2008) Estudo da microestrutura do concreto com adição de cinza volante de casca de arroz residual sem beneficiamento. Dissertação (mestrado), Universidade Federal de Santa Maria, Santa Maria, Brasil.

[25] Pereira, E. (2015) Investigação e monitoramento do ataque por sulfatos de origem interna em concretos nas primeiras idades. Tese (Doutorado), Universidade Federal do Paraná, Curitiba, Brasil.

[26] OLIVEIRA, I. C. (2013) Análises de dados para a elaboração de diretrizes visando à detecção de sulfetos e sulfatos na composição de CCR. Dissertação (mestrado), Universidade Federal do Paraná, Curitiba, Brasil. 